\title{
Adapting Internet of Things to Arduino-Based Devices for Low-Cost Remote Sensing in School Science Learning Environments
}

\author{
https://doi.org/10.3991/ijoe.v17i02.20089 \\ Seok-Hyun Ga, Hyun-Jung Cha ${ }^{(凶)}$, Chan-Jong Kim \\ Seoul National University, Seoul, Republic of Korea \\ todd0906esnu.ac.kr
}

\begin{abstract}
We examine the major technical problems that students experience in authentic scientific inquiry and propose an Arduino-based device, adapting the Internet of Things technology, which is designed for school science in order to solve those technical problems. Three major technical problems as follows: First, it is difficult to have a variety of measuring tools which may satisfy the needs of students. Second, it is hard to equip students with tools befitting the complex inquiry procedures which students develop on their own. Lastly, there exists a problem in which a particular group(s) of students take advantage of their competence in technology and have a monopoly in the process of data analysis. Physical computing and IoT technology can provide solutions to these problems. Development boards like Arduino and Raspberry Pi can be purchased at affordable prices, which allows for measuring devices to be made at low cost by connecting sensors to those boards. Utilizing these development boards may also lead to the possibility to optimize measuring methods or procedures for inquiries of each student. By transmitting the measured data to the IoT Platform, students can have equal access to the data and analyze it easily. We also investigate echnologies used in IoT-applied physical computing including development boards, IoT platforms, and telecommunications technologies. Lastly, as an example of inquiry that adapts physical computing and IoT, we introduce the case of transferring data, measured by a temperature/humidity sensor connected to a development board, to the IoT Platform and visualizing them.
\end{abstract}

Keywords - Science Education Research, Computer-Based Learning, HandsOn Learning, Arduino, Physical Computing, Internet of Things, Scientific Inquiry

\section{Introduction}

With rapid development in technology, our lives have become more connected to scientific technology than ever, and it is almost impossible to think about our lives without technology. Public interest in technology has been growing accordingly, and at the same time, technology itself has been taking a form that is readily accessible to the public. Public interest in technology and the improving accessibility to technology are 
dialectically interacting with and promoting each other. As science and technology are inseparable, the current trend has been constantly stimulating reforms in science education.

One of the important goals of science education is to improve students' scientific reasoning.[1]-[3] In order to accomplish the goal, schools encourage students to participate in a scientific inquiry like observation and/or experiment.[4] Scientific inquiry, which refers to a range of activities from collection and analysis of data to establishment of arguments based on evidences, helps students gain scientific knowledges and develop high-order thinking skills. Chinn, Malhotra distinguished authentic inquiry from simple inquiry. Authentic inquiry, here, refers to scientific activities carried out by students who develop their own research questions and invent complex procedures to address questions of interest.[4] It is difficult for students to generate research questions themselves as well as to invent complex procedures in order to answer their questions. A bigger obstacle, however, is related to technical limitations that often make it difficult for students to implement the complex procedures they have devised. In this article, we find the major technical obstacles students face in authentic inquiry and propose a new inquiry tool based on Arduino adopting the Internet of Things (IoT) designed for scientific inquiry by students.

\section{Technical Limitation in Authentic Inquiry}

Three major problems arising in the process of authentic inquiry by students are as follows: The first issue arises when it comes to having a variety of measuring tools which may satisfy the needs of students. Second, it is difficult to equip students with tools befitting the complex inquiry procedures they invent on their own. Lastly, there arises a problem when a particular group(s) of students or individual(s) competent in technology becomes dominant in the process of data analysis for inquiry.

The first problem is related to the fact that schools need to provide a wide range of measuring tools for students who pursue their authentic inquiry. In authentic inquiry, students generate research problems and select various variables to solve them, which leads to the necessity of various measurement tools.[5] Previously, simple inquiry was carried out under the guidance of teachers who selected variables to measure and made the necessary tools ready for students. Authentic inquiry, however, encourages students to generate their own unique research problems which lead to broadening the range of variables to be measured. Limits in the budget should be considered when schools try to purchase measuring tools to suit the needs of students. For instance, if a student wants to explore the problem of fine dust in a local community and has designed his own inquiry perfectly, it is not possible to pursue his inquiry without a fine dust meter furnished in school. It is not realistic to have every school be equipped with fine dust meters that are not universally needed. Furthermore, it is unclear what type of specifications a student may need for his inquiry and how many devices should be prepared in advance. Even if fine dust monitoring devices are prepared, in the absence of consistent maintenance, they are highly likely to be out of order and end up being discarded with only being used a few times. 
The second problem of having tools to accommodate the complex procedures students invent stems from the fact that students make their own research designs. Authentic inquiry may require different devices depending on the context of the research, even if the same variable is measured. For example, here is a student who wants to measure changes in the fine dust concentration in a specific area for 24 hours in the process of his or her inquiry. Even if there were a very precise fine dust measuring device prepared in the school, it would be difficult for the student to use the device if it requires users to calibrate every time and record the measurement on their own. In this regard, measurement tools used for students' scientific inquiry should be able to measure variables as a matter of course, but at the same time, they need to be capable of supporting students' research design.

The last problem, in which a particular group(s) of students or individual(s) skillful in technology monopolizes inquiry in the process of data analysis stems from limited access to a PC which does not allow more than one student to operate the computer at the same time. Collaborative learning in scientific activities has been recommended as it is believed to encourage student participation and enhance the learning effect.[6] In the collaborative inquiry-based science activities, students carry out scientific reasoning based on the evidence gathered in order to draw reasonable conclusions. Raw data collected from devices developed by physical computing can be one of evidence for scientific reasoning. However, given the setting of measuring tools and the data transmission/storage system, it is inevitable that anyone who accesses the collected data first has priority to data over others. To be specific, if a student gather data from the measuring device connected to a PC, the PC operator will have access to the data before anyone else. If data is stored on a memory card, anyone who reads the memory card first will have priority to data. It is known that, in collaborative learning, students with high academic ability, those who are popular, or male students demonstrate a tendency to dominate the overall activities[7], [8]. In scientific inquiry adapting physical computing, these students are more likely to get prior access to data than others. Having priority in accessing information does not only mean getting data first. Since information itself is power,[9] getting information faster than others is equivalent to having a more dominant position in scientific inquiry.

\section{$3 \quad$ Physical Computing for Authentic Inquiry}

Physical computing can offer an alternative to address the issues mentioned above. In the past, developing a device to measure a specific variable was something that only an expert could do, but the advent of low-cost development boards such as Arduino and Raspberry Pi has opened an era in which anyone can easily develop a device. If you connect a sensor that can measure the variable you want to a development board, a measuring device you have been looking for is just completed. Sensors to be connected to development boards are sold on the Internet at very low prices. China is one of the major countries that manufacture low-cost sensors. The Chinese online shopping sites, like AliExpress, support multilingual services, and ship worldwide. Shipping to Korea is free if you choose to use a regular mail service which may take about 20 to 30 days. 
If you choose the EMS or DHL service, shipping will be done within 7 to 14 days at a cost of about US 20 dollars.

The more powerful advantage of physical computing is that it can customize a measurement device to accommodate each students' own inquiry. First, students can select a sensor with appropriate specifications according to their purposes of inquiry. Even a sensor that measures the same variable may vary in characteristics depending on its kind, having different measurement ranges, accuracy, working voltages, usable temperature/humidity, and prices. Therefore, in inquiry using physical computing, getting to choose a sensor is the biggest benefit that students can enjoy, but at the same time, choosing the right one is the most important and challenging task for them. Furthermore, it is possible to freely design measurement procedures according to the purpose of inquiry. Users are given the right to decide whether measuring takes place only when they want, at regular intervals while power is on, or at a temperature defined in advance.

\section{$4 \quad$ Internet of Things for Authentic Inquiry}

Besides physical computing, IoT plays a very useful role in students' authentic inquiry. First, it can eliminate discrimination of data accessibility found in the process of collaborative learning. Sending collected data to the IoT platform, to which more than one student can access simultaneously, can reduce discrimination of data accessibility. In other words, all students are placed on equal status in terms of accessibility to information.[10] Each student can create his or her own account and, and access authority to devices can be controlled for each account.

The IoT also helps students overcome time and space constraints in their inquiry. Observations using traditional physical computing were difficult to store the collected data systematically. Although it is possible to display data collected in real-time by using display modules such as LCD and OLED, it has a disadvantage of information being volatile. Using secondary memory units to record, data can be stored permanently while students need to load and reorganize data stored on the memory card for each measuring device they employ. On the contrary, there is no need for such cumbersome work when using the IoT platform. Data transmitted from devices is systematically recorded in DBMS of the IoT Platform.

IoT can make the data analysis easy for students. In a traditional inquiry, collected data was organized, charted, and analyzed using desktop-based applications such as Microsoft Excel or LibreOffice Calc. However, since most of IoT platforms have data analysis features including charting, students simply access their accounts and then visualize the collected data on a dashboard they create.

\section{Design}

For the success of scientific inquiry using physical computing, students need to find out which will be most suitable for their scientific inquiry and make a choice from various development boards, sensors, and IoT platforms. Having many options may promise possible advantages in broadening the range of implementation, but it also 
means that teachers or students may need more time to decide which option they should choose for their inquiry. Przybylla pointed out that although ideas for physical computing projects are presented at academic conferences and many teachers express their interest in physical computing at training workshops, it turns out that theoretical and / or practical knowledge about physical computing has not been properly disseminated to teachers.[11] This may be also caused by the fact that each training workshop adopts different technologies, making teachers who are first introduced to physical computing or the IoT technology may think they get to learn something new every time they are at those workshops.

In this article, we would like to propose a suitable configuration for conducting inquiry using physical computing and IoT technology in science education. By doing so, we expect it may help teachers, who want to introduce physical computing and the IoT technology to their classes for the first time, familiarize themselves with cutting-edge technologies with more ease and speed.

What is considered most important in designing is that teachers, who are not professional technicians or engineers, and students should be able to carry out their own scientific inquiry without any help from experts. For example, if a particular IoT platform, whose intuitive UI makes it easy to use, requires professional-level knowledge in server installation, the platform is excluded from the options as it is not something that can be readily used by teachers and students. Technologies at high costs are also avoided. If an LTE module is attached to a development board for communication between the development board and the IoT platform, users are surely advantageous in mobility compared to the Wi-Fi only setting. However, using an LTE module requires a subscription to the LTE network service and leads to the burden of paying bills on a regular basis. Physical computing with IoT largely consists of sensors, development boards, IoT platforms, and wireless communication networks (see Figure 1). As sensors vary depending on the design of inquiry, a common discussion cannot be made. In this regard, we only discuss development boards, IoT platforms, and wireless communication networks below. 


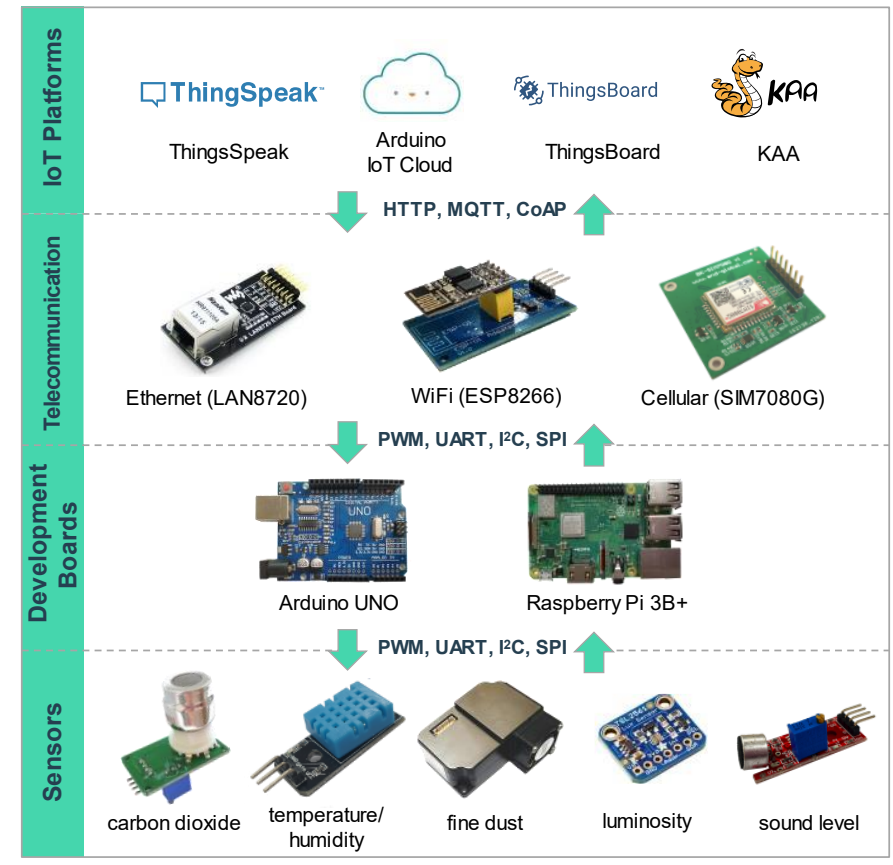

Fig. 1. Composition of IoT-applied Physical Computing

\subsection{Development boards}

Arduino and Raspberry Pi are the development boards mainly used in the field recently, but given the science education environment in school, it is recommended to choose Arduino rather than Raspberry Pi for the following reasons. First, in terms of price, Arduino's unit price is between US 3 and 4 dollars, only one-tenth of Raspberry Pi. Second, when it comes to the installation of an operating system, Arduino does not require firmware or operating system to be installed, but Raspberry Pi needs an operating system to be installed and thus, requires additional knowledge for that. Although Raspberry Pi has a much higher hardware specification than Arduino, which widens its range of application, scientific inquiry in school usually involves simple tasks like measuring variables, storing measured data, and sending it to the IoT Platform wirelessly. Therefore, Arduino is good enough to be used for scientific inquiry in school. Third, given the stability in operating, Arduino is considered more suitable for students than Raspberry Pi. To be specific, in order to make high-specification semiconductors, the production process needs to be more fine-scaled. The more fine-scaled the production process is, the more unstable the electrical properties of chips become. It means that those chips are vulnerable to small electrical shocks from outside. Students who have little electronic knowledge and are new to physical computing are more likely to make mistakes in the wiring process. If students make a mistake when working with 
Arduino, they can simply turn off the power and try to connect it again to have Arduino work normally. However, in such cases, Raspberry Pi is often permanently damaged. Fourth, if we limit our discussion to the development of measuring devices, Arduino has a wider ecosystem than that of Raspberry Pi. Arduino has been widely used to develop measuring devices by different groups of users from amateurs to experts. Various source codes are also shared on GitHub. There have been numerous academic studies conducted using low-cost sensors, focusing on temperature[12], humidity, carbon dioxide[13]-[17], methane[18], fine dust[19]-[28], soil moisture[29], [15], pH[30] and so on.

\section{$5.2 \quad$ IoT platforms}

Although the definition of IoT Platform is not clear[31], if we roughly count the elements commonly found in IoT platforms, it can be defined as software that (1) connects hardware such as sensors and devices, (2) processes communication protocols of various hardware and software, (3) provides security and authentication for devices and users, and (4) stores, analyzes and visualizes the data collected by sensors and devices. As the IoT technology has been used in diverse areas, different IoT platforms have appeared in the industry. While such diversity has the advantage of providing users with a wide range of choices, it also creates confusion for first-time users about what to choose.

Because each area has different needs for IoT Platforms, it is important to choose the right platform depending on the purpose. A platform suitable for scientific inquiry in the school environment should be easy for beginners to install, transmit data from devices, and visualize the collected data. It would be more desirable if the platform supports the exporting function through which users can export the collected data in more universal formats such as Microsoft Excel (*.xlsx) so that they can utilize the data for further inquiry. For non-English-speaking countries, it is also important to consider whether they support multi-locales. The most important thing to consider is if there are any costs incurred from using the platform because students who do not have financial support from schools should be still able to use the platform. The ultimate goal is to enable students who learn IoT technology from scientific inquiry to utilize it in their daily lives not necessarily inside research labs.

Popular IoT Platforms known as suitable for school science education environments include Arduino IoT, ThingSpeak, Kaa Cloud, and ThingsBoard (see Table 1). The fatal disadvantage of Arduino IoT is that third-party boards are not available for free. Students should pay more to use the Arduino genuine board or subscribe to a paid plan at US 6.99 dollars per month. ThingSpeak has limited data visualization capabilities, and Kaa Cloud has limitations in that it only supports English locales. In addition, ThingSpeak, Arduino IoT, and Kaa Cloud support 4 to 5 devices only. However, they are still convenient with the fact that they can be used without additional installation as they are provided through the SaaS(Software-as-a-Service) cloud. ThingsBoard has no limit on the number of devices, supports data visualization, and supports locales of 18 languages. Although ThingsBoard requires its own IoT server, the installation can be easily done with the support of well-made manuals provided on the ThingsBoard website. 
Table 1. Comparison of IoT Platforms

\begin{tabular}{|l|l|l|l|l|}
\hline & \multicolumn{1}{|c|}{ ThingsBoard } & \multicolumn{1}{|c|}{ ThingSpeak } & \multicolumn{1}{c|}{ Arduino IoT ${ }^{\text {a }}$} & \multicolumn{1}{c|}{ Kaa Cloud } \\
\hline Cloud & X & SaaS & SaaS & PaaS \\
\hline Device & unlimited & 4 & 5 & 5 \\
\hline Plot & $\begin{array}{l}\text { chart, gauge, map, } \\
\text { table }\end{array}$ & chart, gauge & chart, gauge, map & $\begin{array}{l}\text { chart, gauge, map, } \\
\text { table }\end{array}$ \\
\hline Export to files & $\mathrm{X}^{\mathrm{b}}$ & $\mathrm{O}$ & $\mathrm{O}^{\mathrm{c}}$ & $\mathrm{X}$ \\
\hline Locale & $\mathrm{O}$ & $\mathrm{X}$ & $\mathrm{X}$ \\
\hline $\begin{array}{l}\text { a. 3rd party boards cannot be used for free. } \\
\text { b. Expert users can export the raw data through PostgreSQL queries. } \\
\text { c. Exporting to Google Spreadsheet is available. }\end{array}$ \\
\hline
\end{tabular}

\subsection{Telecommunication}

For transferring data from development boards to IoT platforms, either wired Ethernet, wireless Cellular, or Wi-Fi can be used. As there exist pros and cons in module prices, network service charges, and mobility depending on which communication method is chosen, it should be considered carefully.

If users want stable communication in a fixed location, Ethernet can be the best choice (see Figure 1). As it is a wired-communication method, there is no interruption due to radio interference. However, the weakness is a lack of mobility because it must be connected directly by wired cable. In addition, for many students to use it in the same location, UTP ports must be installed in each student's seat. Therefore, in the school environment, it is better to use wireless communication such as Cellular and WiFi than Ethernet.

The advantage of using cellular networks is mobility which allows data collection to be done without any limitations in location. Even if the observation point is changed, there is no need to change the settings. However, there is a limitation which requires users to open a new account for the cellular network service and pay the service charges. Recently, there are companies selling SIM cards for the IoT devices. Hologram.io, for example, provides the global roaming service equivalent to a total of 500MB data without limitations of the number of devices connected at US 100 dollars per month. Thingsmobile.com offers global roaming data of up to 500MB for maximum 10 devices at the rate of US 20 dollars per month. Compared to typical mobile phone plans, these services are offered at quite high rates. However, given the differences in network service charge policies adopted in different countries or those of various mobile service providers, it may be premature to decide whether the SIM cards for IoT devices are sold at high prices. To be specific, the SIM808 modules capable of 2G (GSM/GPRS) communication cost around US 9 dollars [12], and the SIM7600E-H modules capable of 2G (GSM/GPRS), 3G (UMTS/HSPA+), and 4G (LTE) communication are between US 35 and 40 dollars. The SIM7020E modules capable of NB-IoT communication, a network specialized for the IoT, are only US 10-15 dollars, more affordable than other LTE modules (see Figure 1). Since the quantity of data collected from measuring variables is not huge, the speed of $2 \mathrm{G}$ mobile communication is good enough. Therefore, it is most desirable to use $2 \mathrm{G}$ modules in the school science environment. However, most of the $2 \mathrm{G}$ modules are based on GSM/GPRS, and some countries (South Korea, North 
Korea, and Japan) do not provide the GSM services, which makes it unavailable for students in South Korea. Since cellular communication is charged according to the amount of data, it is important to minimize the amount of transmitted data. To reduce the data rate, it is recommended to refer to the paper of Yahya et al. [32].

Students, who are familiar with digital devices such as smartphones and thus, have a lot of experiences in using $\mathrm{Wi}-\mathrm{Fi}$, find it easy and familiar to use the Wi-Fi service as a communication method. Students can easily adapt to the $\mathrm{Wi}-\mathrm{Fi}$ environment as they have a good grasp of Wi-Fi characteristics (e.g., SSID and password access, free service in most cases, and possible disconnection in case of being distant from the router). WiFi is the best option for inquiries that measure variables in a fixed space where routers are installed. The biggest advantage of all is that it is a network that students can easily access without anyone's help. However, if students must activate a new account for network service, receive SIM cards, and pay monthly service fees, it would be difficult for them to access that kind of network service. The Wi-Fi modules used primarily in Arduino are ESP-01 which cost around US 1 to 2 dollars and are very affordable compared to the Cellular modules (see Figure 1).

\section{Implementation}

When we introduce physical computing and the IoT technology for low-cost telemetry in the school science environment, Arduino is recommended for a development board and ThingsBoard for the IoT platform. Unless users carry their measuring devices as they move from place to place, using Wi-Fi as the method of connecting to the Internet is the least expensive option to choose. In this article, we introduce one example of IoT observation. We create a device by combining Arduino and ThingsBoard and connecting to $\mathrm{Wi}-\mathrm{Fi}$ in order to measure temperature, humidity, fine dust, and carbon dioxide concentration and apply it to the IoT Platform.

\subsection{Wiring and coding}

The circuit is constructed as shown in Figure 2, and all the parts are purchased from AliExpress. The development board uses Arduino UNO compatible board (US 2.76 dollars), Wi-Fi module ESP-01S (US 1.53 dollars), temperature and humidity sensor DHT11 (US 0.78 dollars), fine dust sensor ZH03B (US 7.98 dollars), and carbon dioxide sensor MG-811 (US 21.66 dollars). Using Arduino IDE, we develop a program with text coding by utilizing libraries opened in GitHub. 


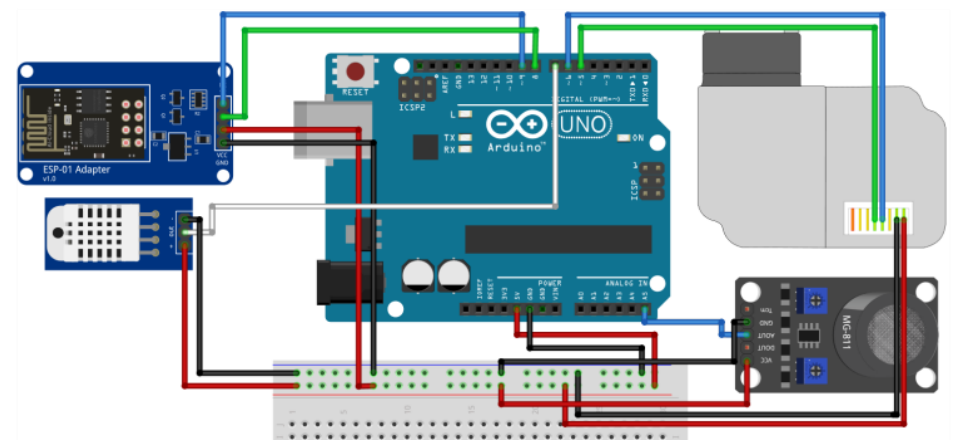

Fig. 2. Fritzing Wiring Diagram for Sensing Temperature and Humidity

\subsection{Installation of ThingsBoard}

ThingsBoard, an open-source software, can be downloaded for free from the website (http://www.thingsboard.io). To use additional features such as exporting to Excel and platform integration, a paid Professional Edition (PE) version should be used, but in the environment for school scientific inquiry, it is not necessary to use the PE version as the Community Edition (CE) already has sufficient functionalities.

The ThingsBoard supports various operating systems, including Ubuntu, CentOS, Windows, Raspberry Pi, and more. Guides and video tutorials available online will help even beginners install it with ease. After the installation is completed, all settings can be modified on the administrator's webpage. Among several features on loT platforms, students mainly utilize the platform to upload the raw data from their devices. So only two menus in the Administrator's page, DEVICES and DASHBOARDS, are used by students (see Figure 3).

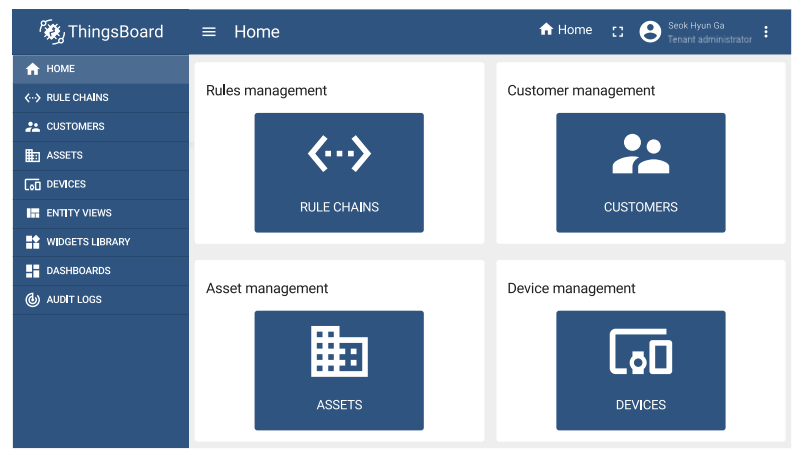

Fig. 3. Administrator page of ThingsBoard

\subsection{Sending data from Arduino to ThingsBoard}

When the ThingsBoard installation is finished, data from Arduino should be sent to the ThingsBoard. The ThingsBoard provides a library which supports Arduino to be 
connected to the IoT Platform without difficulties. In addition, the ThingsBoard website provides an example which describes how to send data measured by DHT11 (temperature and humidity sensor) to the IoT Platform using ESP8266 Wi-Fi modules. The example consists of step-by-step tutorials, which makes it easy for even novices to transmit data. The Arduino UNO, however, has a small Flash memory of 32KB. The ThingsBoard Library may consume a considerable amount of memory because of its library dependencies.[33] In scientific inquiry using Arduino UNO, we only do simple tasks like sending measured data to the IoT Platform, which makes us decide to develop a simplified library ourselves instead of the existing libraries provided by the ThingsBoard.[34].

\subsection{Analysis of data in ThingsBoard}

The data sent to the ThingsBoard is systematically accumulated in the Database Management System (DBMS). The ThingsBoard provides a dashboard function through which data can be visualized and displayed for users' convenience. The strong points that the ThingsBoard dashboard has are the various forms of data visualization it supports including charts, gauges, maps, and tables. This enables students who do not have knowledge in programming languages to visualize the collected data without any difficulties (see Figure 4, 5).

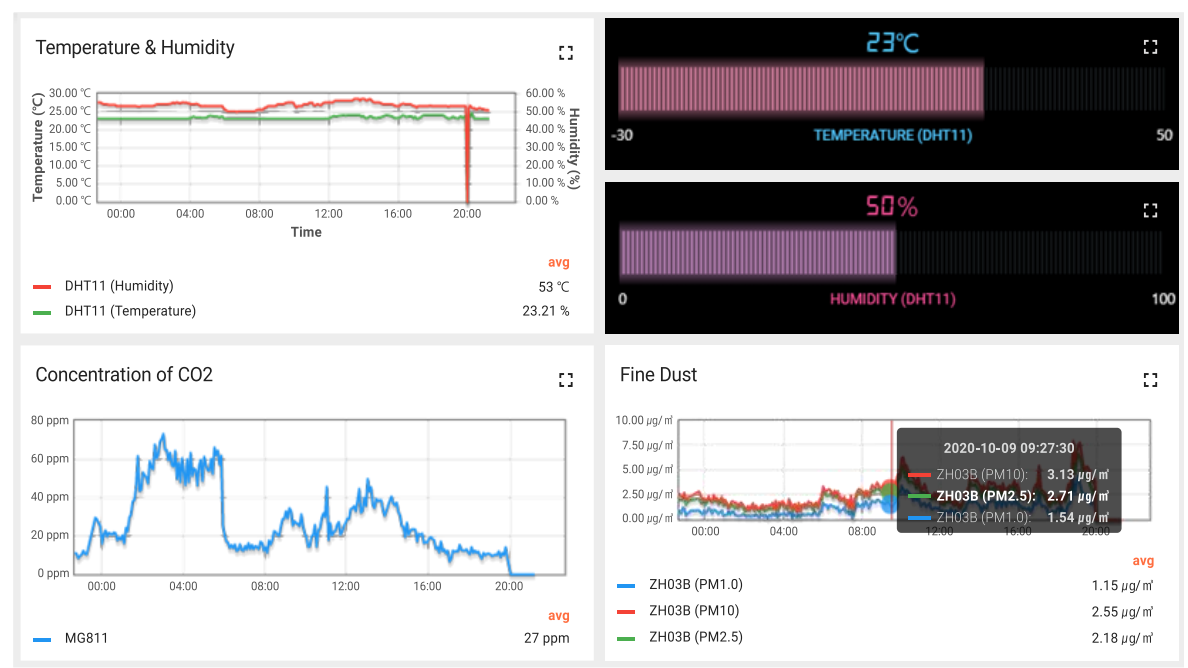

Fig. 4. Chart and Gauge Bar in ThingsBoard Dashboard 

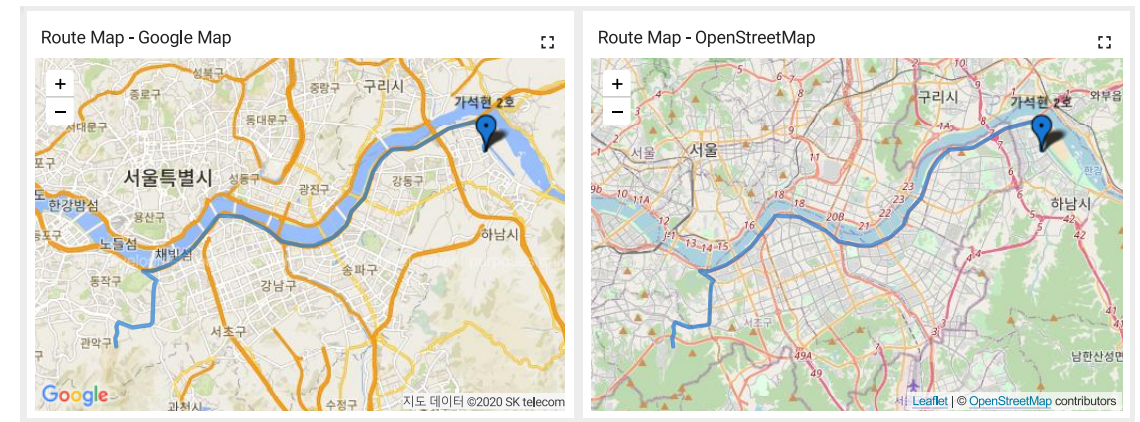

Fig. 5. Google Map and OpenStreetMap in ThingsBoard Dashboard

\section{$7 \quad$ Additional Considerations}

These scientific inquiry activities require competencies and knowledges in various areas including development boards, programming, and sensor operation. If students participate in the activities without clearly setting their goals first, it is highly probable that their attention is drawn to points of minor importance instead of focusing on achieving their ultimate goals. In fact, education courses adopting physical computing have not been quite successful in fulfilling their educational goals as students in those courses concentrated too much on technical aspects only.

If what the activities want to accomplish in the end is scientific inquiry, not computing, it should be ensured that teachers supervise students not to be immersed in technical aspects only. More direct technical support from teachers is needed to steer their classes to scientific inquiry rather than education for computational thinking or coding skills.

\section{$8 \quad$ Associated Content}

The Supporting Information is available on the first author's GitHub (http://www.github.com/shga89).

- The light library for ThingsBoard

- Sample Arduino source code using ThingsBoard (Sensing temperature, humidity, fine dust, and concentration of carbon dioxide)

\section{Acknowledgement}

This work was supported by the National Research Foundation of Korea (NRF) grant funded by the Korean government (Ministry of Science and ICT) (No. 2020R1A2C1014534). 


\section{References}

[1] American Association for the Advancement of Science, Benchmarks for Science Literacy. Oxford University Press, 1994.

[2] National Research Council, Next Generation Science Standards: For States, By States. 2013.

[3] S. Ga, C. Kim, and S. Choe, "Trends of science education research in JRST and IJSE by automatic content analysis from 2008 to 2015," J. Learn.-Centered Curric. Instr., vol. 19, no. 7, pp. 519-543, 2019. https://doi.org/10.22251/jlcci.2019.19.7.519

[4] C. A. Chinn and B. A. Malhotra, "Epistemologically authentic inquiry in schools: A theoretical framework for evaluating inquiry tasks," Sci. Educ., vol. 86, no. 2, pp. 175-218, 2002. https://doi.org/10.1002/sce.10001

[5] C. A. Chinn and C. E. Hmelo-Silver, "Authentic inquiry: Introduction to the special section," Sci. Educ., vol. 86, no. 2, pp. 171-174, Mar. 2002. https://doi.org/10.1002/sce.10000

[6] C. Howe and A. Tolmie, "Group work in primary school science: discussion, consensus and guidance from experts," Int. J. Educ. Res., vol. 39, no. 1, pp. 51-72, Jan. 2003. https://doi.org/10.1016/s0883-0355(03)00073-9

[7] J. A. Bianchini, "Where knowledge construction, equity, and context intersect: Student learning of science in small groups," J. Res. Sci. Teach., vol. 34, no. 10, pp. 1039-1065, 1997. https://doi.org/10.1002/(sici)1098-2736(199712)34:10<1039::aid-tea5>3.0.co;2-s

[8] M. G. Jones et al., "Tool time: Gender and students' use of tools, control, and authority," $J$. Res. Sci. Teach., vol. 37, no. 8, pp. 760-783, 2000. https://doi.org/10.1002/10982736(200010)37:8<760::aid-tea2>3.0.co;2-v

[9] J. Moss, “"Power and the digital divide,"” Ethics Inf. Technol., vol. 4, no. 2, pp. 159-165, Jun. 2002, doi: 10.1023/A:1019983909305.

[10] R. O. Mason, "Four Ethical Issues of the Information Age," MIS Q., vol. 10, no. 1, pp. 512, 1986, doi: 10.2307/248873.

[11] M. Przybylla and R. Romeike, "Physical Computing and its Scope - Towards a Constructionist Computer Science Curriculum with Physical Computing," Inform. Educ., vol. 13, no. 2, pp. 225-240, Oct. 2014. https://doi.org/10.15388/infedu.2014.14

[12] J. P. Sipani, R. H. Patel, T. Upadhyahya, and A. Desai, "Wireless Sensor Network for Monitoring \& Control of Environmental Factors using Arduino," Int. J. Interact. Mob. Technol. IJIM, vol. 12, no. 2, p. 15, Mar. 2018. https://doi.org/10.3991/ijim.v12i2.7415

[13] M. K. Hossain, S. M. Ariful, T. Tower, and S. Bhattacharyya, "GSM based Wireless Sensor Network to Measure Global Warming, Humidity and CO2," Int. J. Comput. Appl., vol. 76, no. 14, pp. 23-29, 2013. https://doi.org/10.5120/13316-0915

[14] Y. S. Kalinin, E. K. Velikov, and V. I. Markova, "Design of Indoor Environment Monitoring System using Arduino," Int. J. Innov. Sci. Mod. Eng., vol. 3, no. 7, pp. 46-49, 2015, doi: 10.1109/IMCEC.2018.8469580.

[15] J. M. Blackstock, M. D. Covington, M. Perne, and J. M. Myre, "Monitoring Atmospheric, Soil, and Dissolved CO2 Using a Low-Cost, Arduino Monitoring Platform (CO2-LAMP): Theory, Fabrication, and Operation," Front. Earth Sci., vol. 7, 2019. https://doi.org/10.3389/feart.2019.00313

[16] P. D. Lapshina, S. P. Kurilova, and A. A. Belitsky, "Development of an Arduino-based CO2 Monitoring Device," in 2019 IEEE Conference of Russian Young Researchers in Electrical and Electronic Engineering (EIConRus), Jan. 2019, pp. 595-597, https://doi.org/10.1109/eiconrus.2019.8656915

[17] H. Pino, V. Pastor, C. Grimalt-Álvaro, and V. López, "Measuring CO2 with an Arduino: Creating a Low-Cost, Pocket-Sized Device with Flexible Applications That Yields Benefits 
for Students and Schools," J. Chem. Educ., vol. 96, no. 2, pp. 377-381, Feb. 2019. https://doi.org/10.1021/acs.jchemed.8b00473

[18] S. Yang, Y. Liu, N. Wu, Y. Zhang, S. Svoronos, and P. Pullammanappallil, "Low-cost, Arduino-based, portable device for measurement of methane composition in biogas," Renew. Energy, vol. 138, pp. 224-229, Aug. 2019. https://doi.org/10.1016/j.renene.2019.01.083

[19] M. Budde, M. Busse, and M. Beigl, "Investigating the use of commodity dust sensors for the embedded measurement of particulate matter," in 2012 Ninth International Conference on Networked Sensing (INSS), Antwerp, Belgium, Jun. 2012, pp. 1-4. https://doi.org/10.1109/inss.2012.6240545

[20] E. Austin, I. Novosselov, E. Seto, and M. G. Yost, "Laboratory Evaluation of the Shinyei PPD42NS Low-Cost Particulate Matter Sensor," PLOS ONE, vol. 10, no. 9, p. e0137789, Sep. 2015. https://doi.org/10.1371/journal.pone.0137789

[21] M. Malika and D. Sarah, "Low-cost air pollution sensors: New perspectives for the measurement of individual exposure?" presented at the 9th International Conference on Urban Climate jointly with 12th Symposium on the Urban Environment, Jun. 2015, [Online]. Available: http://www.meteo.fr/icuc9/Poster/ NOMTM.pdf

[22] V. M. Tasić, M. Jovašević-Stojanović, D. Topalović, and M. Davidović, "Measurement of PM 2.5 Concentrations in Indoor Air Using Low-Cost Sensors and Arduino Platforms," in Proceedings of the 6 th Scientific Meeting EuNetAir, Prague, Czech Republic, 2016, pp. 6972. https://doi.org/10.5162/6eunetair2016/18

[23] M. A. Fathihahet al., "Development of low-cost and user-friendly sustainable portable particulate sensor," IOP Conf. Ser. Mater. Sci. Eng., vol. 458, p. 012041, Dec. 2018. https://doi.org/10.1088/1757-899x/458/1/012041

[24] M. Badura, P. Batog, A. Drzeniecka-Osiadacz, and P. Modzel, "Optical particulate matter sensors in PM2.5 measurements in atmospheric air," E3S Web Conf., vol. 44, p. 00006, 2018. https://doi.org/10.1051/e3sconf/20184400006

[25] H. Pritchard, J. Gabrys, and L. Houston, "Re-calibrating DIY: Testing digital participation across dust sensors, fry pans and environmental pollution," New Media Soc., vol. 20, no. 12, pp. 4533-4552, Dec. 2018. https://doi.org/10.1177/1461444818777473

[26] W. Lenggoro, "Shinyei Based Sensor with Added Roof Enhanced Detection of Indoor Particulate Matter," Int. J. Integr. Eng., vol. 11, no. 7, pp. 67-76, 2019, doi: https://doi.org/10.30880/ijie.2019.11.07.009.

[27] T. Sayahi, A. Butterfield, and K. E. Kelly, "Long-term field evaluation of the Plantower PMS low-cost particulate matter sensors," Environ. Pollut., vol. 245, pp. 932-940, Feb. 2019. https://doi.org/10.1016/j.envpol.2018.11.065

[28] M. Si, Y. Xiong, S. Du, and K. Du, "Evaluation and calibration of a low-cost particle sensor in ambient conditions using machine-learning methods," Atmospheric Meas. Tech., vol. 13, no. 4, pp. 1693-1707, Apr. 2020. https://doi.org/10.5194/amt-13-1693-2020

[29] M. S. Kumar, T. R. Chandra, D. P. Kumar, and M. S. Manikandan, "Monitoring moisture of soil using low-cost homemade Soil moisture sensor and Arduino UNO," in 2016 3rd International Conference on Advanced Computing and Communication Systems (ICACCS), Jan. 2016, vol. 01, pp. 1-4. https://doi.org/10.1109/icaccs.2016.7586312

[30] F. Lezzar, D. Benmerzoug, and I. Kitouni, "IoT for Monitoring and Control of Water Quality Parameters," Int. J. Interact. Mob. Technol. IJIM, vol. 14, no. 16, p. 4, Sep. 2020. https://doi.org/10.3991/ijim.v14i16.15783

[31] F. Paul, "Why are IoT platforms so darn confusing?" Network World, Feb. 05, 2019.

[32] O. H. Yahya, H. Alrikabi, and I. A. Aljazaery, "Reducing the Data Rate in Internet of Things Applications by Using Wireless Sensor Network," Int. J. Online Biomed. Eng. IJOE, vol. 16, no. 03, p. 107, Mar. 2020. https://doi.org/10.3991/ijoe.v16i03.13021 
Paper-Adapting Internet of Things to Arduino-Based Devices for Low-Cost Remote Sensing in School...

[33] "ThingsBoard SDK has dependencies to MQTT PubSub Client, ArduinoJSON, Arduino Http Client."

[34] "The size of the compiled program including this library is about $13 \mathrm{~KB}, 41 \%$ of Arduino UNO's flash memory."

\section{Authors}

Seok-Hyun Ga is a science education researcher, computer scientist, and Ph.D. candidate of Science Education in Seoul National University (SNU), Seoul, Republic of Korea. He received M.S. of Science Education and B.S. of Earth Science Education and Physics Education in SNU, and B.S. of Computer Science in Korea National Open University. His research interests include new technology in education. E-mail: shga@snu.ac.kr

Hyun-Jung Cha is a lecturer of Earth Science Education in Seoul National University and Seoul National University of Education. She received Ph.D. and M.S. of Science Education and B.S. of Earth Science Education in SNU. Her research interested fields include modeling-based science learning, authentic Inquiry, and science teacher expertise. E-mail: todd0906@snu.ac.kr

Chan-Jong Kim is Professor of Earth Science Education in Seoul National University and received Ph.D. from the University of Texas at Austin. He is President of the Korean Association for Science Education (KASE). He served as Dean of College of Education in Seoul National University, President of the Korean Earth Science Society and Chairperson of the International Geoscience Education Organization. His areas of research are action-oriented climate change education, model-based learning in science classrooms, and informal science learning. E-mail: chajokim@snu.ac.kr

Article submitted 2020-11-27. Resubmitted 2021-01-11. Final acceptance 2021-01-13. Final version published as submitted by the authors. 